\title{
Service Poka Yoke
}

\author{
Arash Shahin (Corresponding author) \\ Department of Management, University of Isfahan, Isfahan, Iran \\ 1.242 Saeb Avenue, 81848-13713, Isfahan, Iran
}

Tel: 98-311-793-2040Ｅ-mail: arashshahin@hotmail.com

Maryam Ghasemaghaei

Department of Management, University of Isfahan, Isfahan, Iran

160 Cherryhill place Apt 1209, London ON, N6H 4M4, Canada

Tel: 1-519-702-3586 E-mail: sandra_m_2003@yahoo.ca

\begin{abstract}
In this paper, Poka yoke as one of the effective quality design techniques experienced in manufacturing has been suggested and developed for service fail-safing. For this purpose, the subjects of service failure and service recovery have been introduced. Then, service Poka yoke has been demonstrated and its solutions have been classified. This paper also has proposed a framework, by which the common and uncommon elements of service Poka yoke and Service recovery solutions have been classified and addressed schematically. In the new methodology, service recovery and service Poka yoke are assumed as post and pre solutions on service failure, respectively. The proposed framework seems very helpful for managers as an effective toolbox if they are about to fix problems both at the design and at the delivery stages of the service processes. Finally, some barriers and critical success factors of the application of Poka yoke in services have been discussed.
\end{abstract}

Keywords: Service, Poka Yoke, Failure, Recovery solutions, Framework

\section{Introduction}

Service quality has become a key strategic variable in organizational efforts to both satisfy and retain present customers and also to attract new customers. However, some aspects of service, for example relating to employee actions and customer attitudes, are outside the control of managers. As a result, service failure is inevitable, sometimes mistakes will happen or things will go wrong, and so service recovery action is needed to deal with the mistake or problem and to restore customer satisfaction.(Lewis, 2001).

Much research has focused on how to improve a service provider's service quality, and how to attract and maintain customers (particularly with the use of service recovery techniques). A major factor that affects a customer's perception of a service provider's quality is the number, and extent, of the problems they encounter, and how these problems are handled by the provider. As services are inherently variable in how they are conducted, it is to be expected that problems will occur (Hart et al., 1990). A term that is used synonymously for a problem that a customer has with a service is "service failure". Indeed, the importance of service recovery reinforces the need for organisations to find approaches that are effective in both identifying service failure and in developing strategies to recover successfully. Service recovery should be the cornerstone of a customer satisfaction strategy. (Bamford and Xystouri, 2005).

Customers react in two ways when they encounter a service failure. They either remain with the service provider or leave (i.e. exit). To expand this further, when customers encounter a service failure they can either not complain, or complain and give the service provider an opportunity to rectify the problem. If they choose not to complain, they may remain with the provider, despite their dissatisfaction, or exit. Alternatively, if they complain they may also choose to stay or they may exit (Colgate and Norris, 2001). In order to balance the need for defect-free service and the inevitability of failure, organizations must be pro-active in anticipating likely areas of failures/complaints as well as anticipating the appropriate needs for recovery. They must be swift in their response and must train and empower their employees to respond as well. While this is a large task, the opportunity cost is the risk of losing customers and generating negative word of mouth. (Mack et al., 2000).

A Poka-yoke device is any mechanism that either prevents a mistake or defect occurring or makes any mistake or defect obvious at a glance. It is the concentration on removing the causes of defects that is important (Shingo, 186; 1987). Poka yoke is a way to help people do things right the first time. It does not violate or negate good 
engineering practices. Instead, it expands on those practices to include ways to help people do the job right as well as quickly. One can not prevent all mistakes, but can make it easier to do the job right, although mistakes will still happen. Instead of allowing processes to continue after a mistake has been made, Poka yoke could be used to stop them. Poka yoke is not a new concept. It has been used in the safety area for many years. What is new is to apply those concepts to areas of those processes outside of safety as well.

Shingo did make a clear distinction between a mistake and a defect. Mistakes are inevitable; people are human and can not be expected to concentrate on all the time, or always to understand completely the instructions they are given. Defects result from allowing a mistake to reach the customer, and are entirely avoidable. The goal of Poka yoke is re-designing/engineering the process so that mistakes can be prevented or immediately detected and corrected. Self-checks, and successive checks are used together to gain maximum feedback in the shortest time so that the servicing process is both understood and managed. Although the immediate result is that defects are identified and prevented from progressing, the real aim is to modify the process so that future defects are designed out (Shingo, 1986; 1987). Poka-yoke allows processes to run smoothly as they are fail-safe solutions (Kumar et al., 2008).

Although there exist sufficient resources on the subject of Poka yoke and its application in manufacturing as well as the subject of service recovery, apparently, there are no resources in which the two subjects and their relationship are studied. The aim of this paper is to provide a relatively comprehensive and integrative perspective for service Poka yoke and service recovery and to address their relationship. For this purpose, in the following, the literature on service failure and recovery is reviewed and different types of service Poka yoke are demonstrated. Finally, a framework is proposed, in which, common and uncommon elements of service recovery solutions and service Poka yoke are distinguished and addressed. Finally, the barriers and critical success factors of the application of the proposed framework are discussed.

\section{Service failure and the reaction of customer}

Service failure is inevitable and occurs in both the process and the outcome of service delivery. They include situations when the service fails to live up to the customer's expectations (Michel, 2001). According to Bitner et al. (1990), when failures occur, employee behaviors related to the core service requests for customized service and unexpected employee actions. Bitner et al. (1994), Kelley et al. (1993) and Hoffman et al. (1995) included a typology of problematic customers and added product and policy failures. Additionally, Johnston (1994) classified sources of failure as attributable to the organization or the customers; also, Armistead et al. (1995) offered three types of failures as service provider error, customer error, and associated organizational error (e.g. air-traffic controllers on strike).

There exist various consequences of service failures, namely:

- $\quad$ Dissatisfaction (Kelley et al., 1993);

- A decline in customer confidence (Boshoff, 1997; Boshoff and Leong, 1998);

- $\quad$ Negative word-of-mouth behavior (Bailey, 1994; Mattila, 2001);

- Customer defection (Keaveney, 1995; Miller et al., 1995); and

- A decrease in employee morale and performance (Bitner et al., 1994; Lewis and McCann, 2004).

Customers react in different ways when they encounter a service failure. These include loyalty, voice (e.g. complaining to the service provider, or another party) and exit. These are discussed in the following.

\subsection{Loyalty}

Loyalty is developed over a period of time from a consistent record of meeting, and sometimes even exceeds customer expectations (Teich, 1997). Loyal customers are beneficial to service providers because they often cost less to service, spend more their time with the firm lengthens, and provide a good source for new business (Levesque and McDougall, 1993). They usually lead to lower marketing costs, more efficient operations and higher profits (Mittal and Lassar, 1998). However, loyalty appears in several differing forms which include: pure loyalty, latent loyalty and spurious loyalty (Dick and Basu, 1994). Pure loyalty is patronizing a company often, as well as thinking highly of it. This is the kind of loyalty most people are associated with. Latent loyalty refers to when a customer has a low repeat patronage but thinks highly of the organization. Spurious loyalty, however, is the opposite. It occurs when a customer has a high repeat patronage but a relatively low attitude to the company. Hirschman (1970) captures this notion in the definition of loyalty in the exit, voice and loyalty model, while remaining with a company despite dissatisfaction. 


\subsection{Alike}

Initially, the choice by a spuriously loyal customer to remain with a service provider does not immediately threaten profits, but with continued dissatisfaction, they may spread negative word of mouth or exit (Hirschman, 1970). As Colgate et al. (1996) noted, while it is not always the case that customer defection is the inverse to loyalty, companies need to understand why a customer still patronizes them, as it may not necessarily be a positive and conscious choice. Customers may stay with an organization even if they are dissatisfied, because they perceive they have no choice (Hocutt et al., 1997; Holmlund and Kock, 1996; Mittal and Lassar, 1998; Zeithaml et al., 1996). Hence, a loyal customer may not necessarily be a satisfied customer. The findings from the study conducted by Levesque and McDougall (1993) suggest that even when a problem is not solved, approximately half of the respondents would remain with the firm. This may be due to switching costs, lack of perceived differentiation of alternatives, option constraints on location, time or money constraints, habit or inertia (Bitner, 1990; Ennew and Binks, 1996). Hirschman (1970) also proposes the idea that dissatisfied customers may choose to remain with a service provider in the belief that the likelihood of an improvement outweighs the cost of searching for another supplier.

The literature review suggests that loyalty is one of the responses a customer has to a service failure. However, one should not believe that loyalty is one-dimensional. Customers may stay with a service provider because they have a high opinion of them and see the service failure as an aberration. Customers may also stay after a service failure occurs, because they are spuriously loyal and hence, they feel trapped, apathetic or they do not leave since there is no alternative.

\subsection{Voice}

The terms 'voice' and 'exit' were introduced by Hirschman (1970), when he suggested that dissatisfaction can provoke two active negative responses. Day and Landon (1977) extended the notion of 'voice' further by explaining that voice can be treated as complaining to the service provider, complaining to acquaintances (negative word of mouth), or complaining to third parties in order to help seek redress. Any problem a customers has with their service provider will arouse some emotion whether they complain about it to the provider. By complaining to the service provider, customers give them a chance to rectify the problem. However, a customer must have sufficiently strong emotions about a situation before they make an effort to complain. High transaction costs are another principal reason why consumers choose not to complain. It is important to note that time, cost, and effort involved and uncertainty exists about how to complain (Day and Landon, 1977). Service providers must provide open lines of communication if they want customers to complain, then they can try and solve their problem(s). If a customer voices by any other means (e.g. complaining to a business colleague) or exits, service providers will find it difficult to find out why those customers are unhappy (Levesque and McDougall, 1993). Customer complaints have been identified by the literature as an integral part of service failure. A customer who does not complain may exit and give the organization no chance to 'save' the customer. However, a complaining customer gives the company an opportunity.

\subsection{Stay/exit}

At the end of the day a customer's final decision after a service failure is to reside or leave. Exit is "the voluntary termination of an exchange relationship" (Singh, 1990). In order to exit in response to a service failure, the customer is required to have motivation and expend effort (Singh, 1990; Stewart, 1998).

Customer exit is important because it can cost the seller a great deal of revenue through decreased income from the customer's future revenue, higher costs in attracting new customers, loss of free advertising through word of mouth, and decreased employee retention (Reichheld and Sasser, 1990; Keaveney, 1995; Zeithaml and Bitner, 1996).

The benefits of customer retention have also been emphasized. For example, Reichheld and Sasser (1990) found that by retaining 5 per cent more customers, a service provider can increase profits by almost 100 per cent (Colgate and Norris, 2001).

\section{Pre and post solutions on service failure}

In the following, the two subjects of service recovery and Poka yoke are demonstrated. In fact, it is assumed that the service recovery solution could be used when a service failure has been occurred and the service Poka yoke could be used prior to the occurrence of the failures, hence service Poka yoke is treated as a pre solution and service recovery is treated as a post solution on service failure. 


\subsection{Service recovery}

If service failure does occur, then what can service providers do to recover? When service failures occur, service recovery is the primary way a firm can retain its customers and minimize the costs associated with customer defection and negative word of mouth (Seawright et al., 2008). According to Miller et al. (2000), service recovery involves those actions designed to resolve problems, alter negative attitudes of dissatisfied customers and to ultimately retain these customers; Moreover, it includes situations in which a service failure occurs but no complaint is lodged by the customers (Smith et al, 1999). Johnson (1994) expresses service recovery as to "seek out and deal with service failures". In fact, the "seeking out" distinguishes recovery from complaint handling, as many dissatisfied customers do not complain. The notion of a "service recovery paradox" (i.e. the fact that a successful recovery can result in higher customer satisfaction) suggests that the effective recovery process is crucial for preserving or even improving customer satisfaction (e Cunha et al., 2009).

Successful service recovery has significant benefits. It can

- Enhance customers' perceptions of the quality of the service and the organization;

- Lead to positive word-f-month communication;

- Enhance customer's satisfaction; and

- Build customer relationships, loyalty and impact on profits (Bitner et al., 1990; Spreng et al., 1995; Michel, 2001).

However, the extent of success may depend on

- The type of service (Mattila, 2001);

- The type of failure (McDougall and Levesque, 1999); and

- The speed of response (Boshoff, 1997).

Service recovery can also be poor or ineffective with the consequence that the customer is let down for a second time. This may lead to loss of confidence in the organization and possible defection, together with the spread of negative word-of-mouth communication.

\subsubsection{Service recovery strategies}

Actions that service providers take, in response to defects or failures, comprise a combination of psychological recoveries and tangible efforts, and have been researched by a number of academics. The critical incident technique (i.e. open-ended survey), which allows respondents to highlight any service problem they have encountered in order to identify and assess service recovery strategies, has been addressed and used by Bitner et al. (1990), Kelley et al. (1993), Johnston (1994), Hoffman et al., (1995), Tax et al. (1998), Miller et al. (2000) and Lewis and Spyrakopoulos (2001). The strategies they identified could be classified as:

- Apology;

- Correction;

- Empathy;

- Compensation;

- Follow-up;

- Acknowledgement;

- Explanation;

- Exceptional treatment; and

- Managerial intervention.

An apology and correcting the problem are usually necessary planks of service recovery. The interventions of senior employee management were found to be important by Kelley et al. (1993) and Hoffman et al. (1995); but Lewis and Spyrakopoulos (2001) and Miller et al. (2000) identified benefits, if recovery is handled by front-line staff.

In further studies, written stories are used based on scenario research to describe hypothetical service failures, and alternative service recovery strategies are addressed. Respondents' views on the magnitude of failure and satisfaction levels with recoveries are sought. The effectiveness of recovery strategies (i.e. satisfaction) has been found to relate to: 
- "Level of atonement" (Boshoff, 1997);

- The organization taking responsibility for the failure (Boshoff and Leong, 1998);

- Compensation (McDougall and Levesque, 1999);

- Type of failure (Smith et al., 1999); and

- Type of service (Mattila, 2001).

The most recent research to explain how customers evaluate service recovery efforts is that of justice theory (Tax et al., 1998; Smith et al., 1999; Michel, 2001; Mattila, 2001), which comprises three dimensions as follows:

1). Distributive justice: the perceived fairness of the outcome (e.g. compensation, repairs, replacement). Tax et al. (1998) also highlight the principles of equity, equality and need.

2). Interactional justice: the perceived fairness of the manner in which the customer is treated (e.g. provision of an apology). Demonstrations of politeness, concern, honesty, explanation and the effort put into resolve the problem are also important (Tax et al., 1998).

3). Procedural justice: the perceived fairness of the process used to rectify service failure (e.g. speed of response, accessibility and flexibility of the procedure and company policies).

It can be concluded that the type and magnitude of service failure depend on the industry and service (i.e. outcome- or process-based). Further, the type and effectiveness of service recovery strategies are impacted by:

- The service (Mattila, 2001);

- Purpose of purchase (McDoug all and Levesque, 1999);

- The failure (Smith et al., 1999);

- The magnitude of the failure (Kelley et al., 1993; Smith et al., 1999; Michel, 2001; Mattila, 2001);

- Previous experience with an organization (Tax et al., 1998); and

- Service recovery expectations (Miller et al., 2000; Lewis and McCann, 2004).

According to Johnston and Michel (2008), Service recovery procedures appear to have a greater impact on employees and process improvement than on customers.

\subsubsection{Service recovery elements}

Service recovery elements include (Bamford and Xystouri, 2005):

- Acknowledge the challenge of delivering service excellence;

- Adopt a "total" systems approach;

- Strive for consistency with personalization in service delivery;

- Understand customers and anticipate their needs;

- Listen to both customers and front-line staff;

- Log compliments and complaints;

- Continuously training and motivate the front-line staff;

- Provide dedicated resources for communication and motivation;

- Manage the organization with an eye for the detail in everything; and

- Focus, above all, on delivering consistently high quality at a profit for the company.

\subsection{Poka yoke in services}

Poka yoke or fail-safing, in its simplest form, is about designing a production process so that a specific error cannot occur. In other words, it prevents failures and therefore it seems reasonable to refer to it as a pre solution to service failures, comparing with service recovery, which aims to mitigate the effects of failures and is referred to as post solution in this study. An example for Poka yoke is the vending machines that cannot negotiate silver dollars are designed with slots too small to accept them. The concept was first coined and practiced as poka-yoke by Shingo at Toyota, and is often used as a low cost and intuitive tactic in the implementation of TQM within the manufacturing environment. Although Shingo's efforts were focused on the manufacturing industry, the Poka yoke concept can have even more merit in the service sector. In both areas the customer is the mainstay. However, in the service sector it becomes a challenge to place a statistical measurement on the intangible aspects 
of customer service (Foster, 2001). As a result, Poka yoke could have a great impact in the service industry because it places fail-safe measures on processes that can make a difference in maintaining a relationship with the customer. It only requires a good or bad value placement on the process. Chase and Stewart (1994) argue for more aggressive use of fail safing in service processes via a brief compendium of examples and provide a modest framework to inspire such usage.

Customer participation and perception must be managed to achieve total quality within service, and so classify the underlying errors to be fail-safed as either server-based or customer-based. Server based errors are further delineated as within the task, treatment, or tangible dimension of the service. Server task errors involve incorrect server performance such as improper arrangement of surgical instruments by operating room staff; indented holding trays exemplify a Poka yoke preventing such error. Server treatment errors relate to their behaviors during customer contact; Eye contact establishes a relationship between the customer and the sales person (Henricks, 1996). If customers equate eye contact during a personal service encounter with high quality, transaction forms requiring the server to indicate the eye color of the customer constitutes effective fail safing. Tangible (i.e., physical and environmental) server errors can also be fail safed; bus station benches are designed as sequential chairs with fixed armrests to prevent transients from sleeping on them, and hotels use paper strips around clean linens to ensure the detection of use by housekeeping. Customer-based errors occur before, during, and after the service encounter. Customer preparation errors include inadequate service access or customer expectation management. Dental patients often forget appointments between intervals; the error is generally fail-safed via a telephone call or post card shortly before the scheduled service. The spectrum of customer errors during the encounter include incorrect flow or queue, needs specification, or coproduction. Cable TV subscribers often request service calls when they have unknowingly changed the required channel setting; the needs determination process is poka-yoked by always requiring the customer to change from, then back to, the required setting.

Chase and Stewart state that poka-yoke involves a three steps process of initially identifying an error, tracing the error to its source, then developing and implementing the related fail safe. The authors demonstrate the systematic fail safing of a small automotive service process (Table 2). The operation is flowcharted along a sequential horizontal axis; the vertical axis reflects the level of customer involvement (e.g., front office versus back office) that in turn implies the appropriate type of service poka-yoke as it is addressed in Table 1. We can conclude that fail-safing should be employed as a primary quality tactic in services, compared to its current secondary role in the production of goods, due to its intimacy with product design; and, furthermore, that poka-yoke offers service managers a practical approach to immediate gains in quality.

Chase and Stewart (1994) appropriately pursue a more systematic approach to customer server relationship management during its critical 'moments of truth, a relationship that practitioners often view as too nebulous to manage for total quality. Their advocacy of fail-safing as first response represents a pragmatic and parsimonious approach that recognizes the current and significant disparity between manufacturing and service quality. Many of the examples within the article do not represent true poka-yokes; rather than providing assurance or prevention of errors, they tend to merely foster or encourage their minimization. Service process errors often immediately and irrevocably translate into defective service products, and so require the process goal of zero first time defects. Such a goal is not attainable through statistical monitoring of the dynamic marketplace; it can only be assured through the proaction that poka-yoke provides.

\subsubsection{Two classes of service Poka-yoke strategies}

Literature review does not provide a generic classification for service Poka-yoke strategies. One of the recent investigations is the work of Kumar and Steinebach (2008) who used service Poka-yoke for prevention of medical errors. They referred to Chase et al. (2005) who classified the subject into three ways (three T's):

1) Task to be done (was the patient's broken leg fixed right?);

2) Treatment accorded to the customer (was the caregiver courteous or did the doctor pay sufficient attention to the patient?); and

3) Tangible and environmental features of the service facility (was the emergency room desensitized?)

Chase and Stewart (1994) classify service poka-yoke strategies by the type of error they are designed to prevent as server errors and customer errors. Server errors result from the task, treatment, or tangibles of the service. Customer errors occur during preparation, the service encounter, or during resolution. Task errors include doing work incorrectly, work not requested, work in the wrong order, or working too slowly. Some examples are presented in Appendix 1. 


\subsubsection{Service Poka yoke: some case examples}

Following the discussion, some of the experiences of the authors are classified and presented here as case examples of service Poka yoke. The authors have classified those cases in three categories as layout, self-service and technology. However, the following classification are considered as enablers for the strategies addressed and classified in section 7.2.1:

1) Layout

- In most of places when people want to park their cars, they usually park horizontally along the road; however in some places people park somehow vertically and it helps them to have more chances for finding a place for parking. This is usual for busy areas and the road should be wide enough for such an arrangement (e.g. downtown of New York).

- When stores put the price label on goods, buyers do not need to ask the price and it helps the sales person to deliver services in a more organized manner.

- In some palces after the customer have food, the waiter put his/her bill on the table. It prevents the counter to be crowd and customers need not to stay in queue for paying the food bill (e.g. a restaurant of a 5 star hotel versus the long queues of McDonald's food stors).

- In many services such as a conference, the organizers are usually asked to wear uniforms with different colors or to use representation cards in different colors. Therefore, the audiences could easily access the responsible persons. Other examples include personnel in banks, hotels, etc. Also, the variety of color could be useful in distinguishing the departments. For instance, in a hospital using different color bands in buildings, directs patients to their destinations.

- Location of minor surgery at the main entrance of hospitals. This not only saves patients' time, who need short services, but also enables the hospital to prevent having crowded areas in other inside departments, where patients need longer time for treatment.

- Using different shelves for storing goods with different sizes in department stores or different books in libraries. For instance, in some libraries, such as the Robinson library at the University of Newcastle, even the floors separates different sizes of books; large books are available in level 2 and ordinary ones are in level 3; old journals are available in level 3 and new ones (since 5 years ago) are in level 4.

- Using double doors in building to avoid noise (e.g. hospitals and libraries).

2) Self-services

- Self services (e.g. restaurants).

- In some airports, all types of planes stay in one location (i.e. gate) comparing to other airports in which, they stay in different locations. This implies a self-service maintenance facility, although it could also be related to the layout category. However, this kind of layout provides an easier and more cost efficient layout for the airport due to the specialized maintenance facilities located in each of the gates, providing similar services for a series of special type of planes (e.g. Schiphol international airport in Amsterdam versus Dubai international airport).

- Self service machines; for instance, machines used for measuring blood pressure and weight; food and juice/ copy machines/ automatic washing machines processing by coins/credit cards.

- In some libraries, the readers do not have access to the shelves and the librarian receive the order and bring them the requested book. In others, the readers could easily go to the shelves and collect them individually. Having access to the copier machines by the readers is another example.

3) Technology

- In some supermarkets when people want to use trolleys, they should put a coin in a small box on them to release one. Once their shopping is finished and they want to leave there, they turn back the trolley to the specific area outside the supermarket and by locking it to other trolleys, they could collect their coin back. This helps the supermarket to better manage the internal space. This case example could also be considered in the layout category, since the trolleys are located in a place out side of the store and also in the self-service category, because it is the customers who are actually responsible for handling the trolleys (e.g. NETTO versus AZDA).

- Most of airports use some flexible tunnels instead of stairs for transferring passengers to the airplane. This case example could also be considered in the layout category, since it reduces the needed space for movement of facilities. 
- Using electrical automatic stares in public sectors, which facilitates the movement of people, and specially those who are carrying heavy bags or are somehow disable to use stairs.

- The increasing use of internet facilities for delivering services, such as e-shopping, e-registering, e-procurement, etc.

- Using digital boards to announce the number or the name of customers orderly (e.g. names of customers in a clinic or number of encounters in a post office).

- Using credit cards for payments instead cash payments.

- Using wireless phones by referees in field games, such as football.

\section{New methodology: A comprehensive perspective for the integration of service recovery and Poka yoke}

The authors feel that a framework is useful to comprehensively categorize the strategies and illustrate their relationships. As it is shown in Figure 1, service failures, recovery solutions and Poka yoke strategies are categorized and their common and uncommon components are distinguished. The Figure implies an important message, which is the fact that some of the Poka yoke strategies have the potential to be realized as the improving design aspects of services (i.e. the uncommon components in the right circle). The three categories addressed in section 3.2.2 could be used as enablers for effective implementation of the Poka yoke strategies addressed in Figure 1, which in turn are taken from the literature and section 3.2.1. The common components are those which are dependent on the state of service processes. If for instance empathy is used as a means to consider customer requirements and to satisfy them in the next stages of service delivery, it could be treated as a pre solution; but if empathy is used for consideration of customer complaints, it could be treated as a post solution for service failures. However, the proposed framework seems very helpful for the managers to be used as an effective toolbox if they are about to fix problems both at the design and at the delivery stages of the service processes.

In practice, the proposed framework is dependent upon the organization's quality strategy. Considering three strategies of "quality of performance", "quality of conformance" and "quality of design" (Juran, 1995), if the quality strategy is focused on "quality of design", then the organization could emphasize more on pre solutions such as Poka yoke strategies; if the focus is on "quality of performance", it could emphasize more on the post solution strategies; and finally, if the strategy of "quality of conformance" is undertaken, the common strategies addressed in the framework could be considered. However, if the service organization decides to apply any of the strategies, the case examples provide good means for understanding the applicability of Poka yoke in the framework.

\section{Discussion and conclusions}

In this paper, Poka yoke was suggested and developed for service fail-safing. The subjects of service failure and service recovery were introduced. Furthermore, service Poka yoke was demonstrated and its solutions were classified. Some case examples were also presented in three categories as layout, technology and self-service for a better understanding of the subject following by a new framework proposed for designing fail safe services. As it was demonstrated and discussed in this paper, different strategies were addressed for improving service processes, which in turn enhance customer satisfaction.

It is important to note that not all service Poka yoke projects lead to success. A number of barriers and critical success factors exist, on which the managers and designers should concentrate carefully. Although as it was mentioned in this paper, the Poka yoke in services are different from the Poka yoke in manufacturing applications, its barriers and success factors seem to be similar. However, Patel et al. (2001) suggest the following critical success factors for implementing a Service Poka yoke:

- Audit and review to verify the existence of mistake proofing methods; check that the methods are being followed; and assess the effectiveness of the methods.

- Operators need to be trained on how to use and apply mistake proofing devices.

- Employee participation and suggestion schemes are important in helping the design of Poka yoke devices, either individually or through team work. Those employees making a contribution to these activities need to be recognized.

- Management support is needed to encourage the design and implementation of Poka yoke system.

- It is important to undertake a cost-benefit analysis/feasibility study and/or risk assessment to evaluate whether investment mistake proofing is viable and beneficial. 
Patel et al. (2001) also address the following barriers to the implementation of Poka yoke:

- Difficulty in accepting change, resulting in hostility and fear of job losses.

- Operators and engineers make fun of the word "Poka yoke" by expressing the comment "doing the Poka-yoke". Some of the managers and employees might express the view that they do not need to use these methods to reduce errors and they prefer to stick with what they regard as the tried and tested methods (e.g. work study) and intuition.

- Carrying out planning and evaluation tasks are considered difficult for companies where processes are running constantly.

- Justifying investment relating to mistake proofing is sometimes difficult as it often considered as too expensive, reflecting a lack of management interest in pursuing these types of improvement.

- The methods used for Poka yoke may be inappropriate and ineffective, so a new alternative has to be found, which consumes more time and effort and sets back the implementation plan. The facts imply that if you do not succeed at first, learn from the mistakes, persevere and plan improvements from failures.

- Even when Poka-yoke devices are implemented, people do not respect them and carry on with the traditional way of working.

In addition to the above potential obstacles/critical success factors, limitations of the implementation of the proposed framework should be realized. Some of the major limitations include difficulty in distinguishing quality strategies and their corresponding pre and post solutions, i.e. strategies in the proposed framework. This in turn, might affect the perception of personnel who are the providers of services to customers. In other words, if the post solutions are allowed and simultaneously the pre solutions are emphasized, the personnel might feel confused on the duality of quality strategies of the organization. The difficulty of cost-benefit analysis of the pre and post strategies is another important obstacle, which is due to the intangibility of services, which in turn makes it difficult to measure them and therefore, makes it hard to trade-off between pre and post solutions. Another important limitation of the application of the proposed framework is related to the type and dimensions of service organizations. For instance, if the quality strategy of the organization encompasses all the three strategies of quality of design, conformance and performance and there exist problems and limitations in organizational resources in implementing the whole proposed framework, then due to the fact that some strategies are not feasible to use, the proposed methodology might seem not effective as expected.

However, it is important to note that improvement and design of service processes are more difficult than the manufacturing processes. An important question is that how much a service company should invest on designing defect free services? In advanced quality engineering techniques such as Six Sigma, the practitioners believe that comparing to the manufacturing companies, not all the service companies do necessarily need to be improved to the high levels of quality, such as five or Six Sigma. Of course, this does not mean that the subject of this paper is only limited to a few number of service applications, rather considering the different case examples, a service company could use any of the options of layout, self-service and technology depending on its capabilities and budget constraints.

Although the discussions, proposed framework and case examples seem very helpful for the managers who seek how to fix problems at different stages of the service processes, future research should also investigate the possible influence the application of the proposed framework on the service organizations. Moreover, considering the addressed critical success factors and barriers, using different strategies and solutions of service Poka yoke might lead to a competitive advantage/disadvantage. Future research should also develop cost benefit analysis of the strategies and solutions and address the corresponding tradeoffs.

\section{References}

Armistead, C.G., Clark, G., \& Stanley, P. (1995). Managing Service Recovery, Cranfield: Cranfield School of Management.

Bailey, D. (1994). Recovery from customer service shortfalls. Managing Service Quality, 4(6), 8-25.

Bamford. D., \& Xystouri, T. (2005). A case study of service failure and recovery within an international airline. Managing Service Quality, 15(3), 306-322.

Bitner, M.J. (1990). Evaluating service encounters: the effects of physical surroundings and employee responses. Journal of Marketing, 52(2), 69-82.

Bitner, M.J., Booms, B.H. \& Tetreault, M.S. (1990). The service encounter: diagnosing favorable and 
unfavorable incidents. Journal of Marketing, 54(1), 71-84.

Bitner, M.J., Booms, B.H., \& Mohr, L.A. (1994). Critical service encounters: the employee's viewpoint. Journal of Marketing, 58(4), 95-105.

Boshoff, C. (1997). An experimental study of service recovery options. International Journal of Service Industry Management, 8(2). 30-110.

Boshoff, C., \& Leong, J. (1998). Empowerment, attribution and apologising as dimensions of service recovery: an experimental study. International Journal of Service Industry Management, 9(1), 24-47.

Chase, R., \& Stewart, D. (1994). Make Your Service Fail-Safe. Sloan Management Review, 35(3), 35-44.

Chase, R.B., Jacobs, R.F., \& Aquilano, N.J. (2005). Operations Management for Competitive Advantage. New York, NY: McGraw-Hill Irwin.

Colgate, M., \& Norris, M. (2001). Developing a comprehensive picture of service failure. International Journal of Service Industry Management, 12(3), 215-233.

Colgate. M., Stewart, K., \& Kinsella, R. (1996). Customer Defection: a study of the student market in Ireland. International Journal of Bank Marketing, 14(3), 9-23.

Day, R.L., \& Landon, E.L.J. (1977). Toward a theory of consumer complaining behavior. In A.G. Woodside, J.N. Sheth \& P.D. Bennett (Eds.), Consumer and Industrial Buying Behavior (pp. 425-437). New York, NY: North-Holland.

Dick, A.S., \& Basu. K. (1994). Customer loyalty: toward an integrated conceptual framework. Journal of the Academy of Marketing Science, 22(2), 99-113.

e Cunha, M.P., Rego, A., \& Kamoche, K. (2009). Improvisation in service recovery. Managing Service Quality, 19(6), 657-669.

Foster, S.T. (2001). Managing Quality An Integrative Approach. New Jersey: Prentice Hall.

Hart, C.W.L., Heskett, J.L., \& Sasser, W.E. (1990). The profitable art of service recovery. Harvard Business Review, 68(4), 148-156.

Henricks, M. (1996). Make No Mistake. Entrepreneur, 24(10), p.86.

Hirschman, A.O. (1970). Exit voice and loyalty: Responses to Decline in Firm, Organizations, and States. Cambridge, MA: Harvard University Press.

Hocutt, M.A., Mowen, J.C., \& Chakraborty, G. (1997). A Model of Relationship Dissolution: Antecedents and Consequences of a Buyer-Seller Relationship. Chicago, IL: American Marketing Association.

Johnston, R. (1994). Service Recovery: An Empirical Study. Coventry: Warwick Business School.

Johnston, R., \& Michel, S. (2008). Three outcomes of service recovery - Customer recovery, process recovery and employee recovery. International Journal of Operations \& Production Management, 28(1), 79-99.

Juran, J. (1995). Managerial Breakthrough: the classic book an improving management performance. New York, NY: Mc Graw-Hill.

Keaveney, S.M. (1995). Customer switching behavior in service industries: an exploratory study. Journal of Marketing, 59(2), 71-89.

Kelley, S.W., Hoffman, K.D., \& Davis, M.A. (1993). A typology of retail failures and recoveries. Journal of Retailing, 69(4), 429-432.

Kumar, S., \& Steinebach, M. (2008). Eliminating US hospital medical errors. International Journal of Health Care Quality Assurance, 21(5), 444-471.

Kumar, S., Strandlund, E., \& Thomas, D. (2008). Improved service system design using Six Sigma DMAIC for a major US consumer electronics and appliance retailer. International Journal of Retail \& Distribution Management, 36(12), 970-994.

Levesque, T.J., \& McDougall, G.H.G. (1993). Managing customer satisfaction: the nature of service problems and customer exit, voice and loyalty. Asia Pacific Journal of Quality Management, 2(2), 40-58.

Lewis, B., Clacher, E., \& McCann, P. (2004). Service failure and recovery: evidence from the hotel industry. International Journal of Contemporary Hospitality Management, 16(1), 6-17.

Lewis, B.R., \& Clacher, E. (2001). Service failure and recovery in UK theme parks: the employees perspective. 
International Journal of Contemporary Hospitality Management, 13(4), 166-175.

Mack. R., Mueller, R., Crotts, J., \& Broderick, A. (2000). Perceptions, corrections and defections: implications for service recovery in the restaurant industry. Managing Service Quality, 10(6), 339-346.

Mattila, A.S. (2001). The effectiveness of service recovery in a multi-industry setting. The Journal of Services Marketing, 15(7), 596-583.

McDougall, G.H.G., \& Levesque, T.J. (1999). Waiting for service: the effectiveness of recovery strategies. International Journal of Contemporary Hospitality Management, 11(1), 6-15.

Michel, S. (2001). Analyzing service failures and recoveries a process approach. International Journal of Service Industry Management, 12(1), 20-33.

Miller, J.L., Craighead, C.W., \& Karwan, K.R. (2000). Service recovery: a framework and empirical investigation. Journal of Operations Management, 18(4), 387-400.

Mittal, B., \& Lsser, W.M. (1998). Why do customers switch? The dynamics of satisfaction versus loyalty. The Journal of Service Marketing, 12(3), 94-177.

Patel, S., Dale, B.G., \& Shaw, P. (2001). Set-up time reduction and mistake proofing methods: an examination in precision component manufacturing. The TQM Magazine, 13(3), 175-179.

Reichheld, F.F., \& Sasser, W.E. Jr. (1990). Zero defections: quality comes to services. Harvard Business Review, 68(5), 105-111.

Seawright, K.K., DeTienne, K.B., Bernhisel, M.P., \& Hoopes Larson, C.L. (2008). An empirical examination of service recovery design. Marketing Intelligence \& Planning, 26(3), 253-274.

Shingo, S. (1986). Zero Quality Control: Source Inspection and the Poka-Yoke System. Portland, OR: Productivity Press.

Shingo, S. (1987). The Sayings of Shigeo Shingo: Key Strategies for Plant Improvement. Portland, OR: Productivity Press.

Singh, J. (1990). Voice, exit, and negative word-of-mouth behaviors: an investigation across three service categories. Journal of the Academy of Marketing Sciences, 18, 1-15.

Smith, A.K., Bolton, R.N., \& Wagner, J. (1999). A model of customer satisfaction with service encounters involving failure and recovery. Journal of Marketing Research, 36(3), 356-389.

Stewart, K. (1998). An exploration of customer exit in retail banking. International Journal of Bank Marketing, 16(1), 6-14.

Tax, S.S., Brown, S.W., \& Chandrashekaran, M. (1998). Customer evaluations of service complaint experiences: implications for relationship marketing. Journal of Marketing, 62(2), 7-60.

Teich. I. (1997). Holdings on to customers: the bottom line benefits of relationship building. Bank Marketing, 29(2), 12-13.

Table 1. Six types of service Poka-Yoke (Chase and Stewart, 1994)

\begin{tabular}{|l|l|l|l|}
\hline Error by & Type & Example Error & Example Fail-safe \\
\hline Server & Task & Disarranged surgical instruments & Indented trays in OR \\
Server & Treatment & Lack of eye contact & Eye color checklist on form \\
Server & Tangible & Soiled linens not replaced & Paper strips on clean linen \\
Customer & Preparation & Dental appointment forgotten & Post card as reminder \\
Customer & Encounter & Service call for wrong channel setting & Resetting of channel as part of needs determination \\
Customer & Resolution & Quality survey not completed & Attach survey to POS checkout process \\
\hline
\end{tabular}


Table 2. Examples from fail-safed automotive service process (Chase and Stewart, 1994)

\begin{tabular}{|l|l|l|l|}
\hline Customer Error & Customer Fail-safe & Server Error & Server Fail-safe \\
\hline Can't communicate need & $\begin{array}{l}\text { Server repeats understanding for } \\
\text { confirmation }\end{array}$ & $\begin{array}{l}\text { Incorrect data on } \\
\text { work order }\end{array}$ & $\begin{array}{l}\text { Maintain vehicle and } \\
\text { customer database for } \\
\text { preprinted orders }\end{array}$ \\
Can't be located & $\begin{array}{l}\text { Beeper issued on arrival } \\
\text { Clear and informative signs and } \\
\text { Can't find service area }\end{array}$ & $\begin{array}{l}\text { Arrival unnoticed } \\
\text { Not served in arrival } \\
\text { order }\end{array}$ & $\begin{array}{l}\text { Numbered markers on } \\
\text { vehicles }\end{array}$ \\
Doesn't under-stand & Pehicle arrival at \\
service required & explanations and graphics & $\begin{array}{l}\text { Bill print as electronic } \\
\text { kanban for vehicle }\end{array}$ \\
& & long & \begin{tabular}{l} 
retrieval by runner \\
\hline
\end{tabular}
\end{tabular}

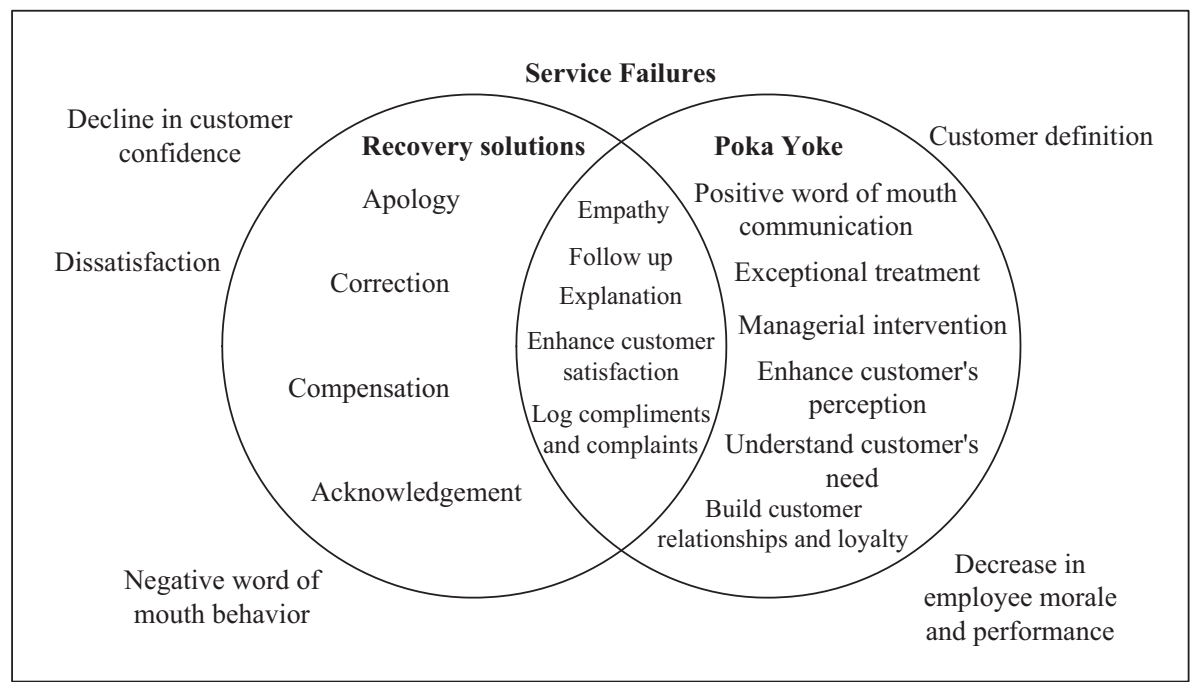

Figure 1. A comprehensive framework for designing fail-safe services

Appendix 1. Two classes of service Poka-yoke strategies: some examples (Chase and Stewart, 1994)

1) Service Poka yoke strategies

\begin{tabular}{|l|l|}
\hline \multirow{3}{*}{ Task } & - Incorrect work \\
& - Work not requested \\
& - Work completed in the wrong order \\
\hline \multirow{2}{*}{ Treatment } & - Failure to acknowledge the customer \\
& - Failure to listen to the customer \\
& - Failure to react appropriately to the customer \\
\hline
\end{tabular}

2) Customer Poka yoke strategies

\begin{tabular}{|l|l|}
\hline \multirow{3}{*}{ Preparation } & - Failure to have materials available \\
& - Failure to understand their role in the transaction \\
\hline \multirow{3}{*}{ Encounter } & - Failure to engage in the correct service \\
& - Failure to remember steps in service process \\
& - Failure to follow system flow \\
Resolution & - Failure to specify desires \\
& - Failure to follow instructions \\
& - Failure to signal service failures \\
& - Failure to learn from experience \\
& - Failure to execute post encounter actions \\
\hline
\end{tabular}

